\title{
Hippocampal Dopamine Receptors Modulate the Motor Activation and the Increase in Dopamine Levels in the Rat Nucleus Accumbens Evoked by Chemical Stimulation of the Ventral Hippocampus
}

\author{
Teodoro Zornoza', María J Cano-Cebrián', Marta Miquel², Carlos Aragón ${ }^{2}$, Ana Polache' and \\ Luis Granero*,I \\ 'Department de Farmàcia i Tecnología Farmacèutica, Facultat de Farmàcia, Universitat de València, Burjassot, Spain; ${ }^{2}$ Área de Psicobiología, \\ Universitat Jaume I, Castelló, Spain
}

\begin{abstract}
A number of studies have shown that chemical stimulation (using N-methyl-D-aspartate (NMDA) infusions) or electrical stimulation of the ventral hippocampus $(\mathrm{VH})$ elicits locomotor activation and sustained increases in nucleus accumbens (NAc) dopamine (DA) levels in rodents. How DA neurotransmission in NAc is involved in these effects has also been well established. However, the modulatory role of the DA receptors located in $\mathrm{VH}$ is not yet fully understood. The purpose of this study was to characterize the role played by $\mathrm{VH} \mathrm{DI}$ and D2 subtype receptors in both the locomotor activation and NAc DA increases induced by NMDA stimulation of the VH. This was assessed by studying how retrodialysis application of NMDA $(50 \mathrm{mM}, 10 \mathrm{~min})$ affects motor activity and NAc DA levels during simultaneous retrodialysis administration of the DI/D5 receptor antagonist SCH 23390 ( 100 and $250 \mu \mathrm{M}, 60$ min) or the D2 receptor antagonist raclopride ( 100 and $250 \mu$ M, 60 min). SCH 23390 attenuated or completely abolished NMDA-evoked locomotor activation and the concurrent increase in NAc DA levels. On the other hand, raclopride was initially able to attenuate the effects of VH NMDA stimulation. However, in the last phase of the experiments, animals showed an important increase in clonic seizure activity with a simultaneous and dramatic increase in NAc DA levels. Our results show that the NMDA receptor-mediated effects in the VH require both DI and, probably, D2 receptors and suggest that DA in VH strongly modulates the excitatory outputs from this brain area. Neuropsychopharmacology (2005) 30, 843-852, advance online publication, 2 February 2005; doi: I0.1038/sj.npp. I 3006 I 8
\end{abstract}

Keywords: DI; D2; ventral hippocampus; nucleus accumbens; NMDA; locomotor activity; dopamine

\section{INTRODUCTION}

Local infusions of $N$-methyl-D-aspartate (NMDA) in the ventral hippocampus (VH) have been found to elicit locomotor activation in rodents (Yang and Mogenson, 1987; Wu and Brudzynski, 1995; Brudzynski and Gibson, 1997; Bardgett and Henry, 1999; Legault and Wise, 1999; Giménez-Llort et al, 2002). Similarly, NMDA infusion in the $\mathrm{VH}$ also induces robust and sustained increases in extracellular dopamine (DA) levels in the nucleus accumbens (NAc) of rats, which are apparently correlated with the time course of increased locomotor activity (Brudzynski and Gibson, 1997; Legault and Wise, 1999; Legault et al,

\footnotetext{
*Correspondence: Dr L Granero, Facultat de Farmàcia, Farmacia i Tecnologia Farmaceutica, Universitat de València, Avda Vicente Andres Estelles s/n, 46100 Burjassot, Spain, Tel: + 34 963544910, Fax: + 34 9635449 II, E-mail: Ifgran@uv.es

Received 21 July 2004; revised and accepted 15 October 2004 Online publication: 18 October 2004 at http://www.acnp.org/citations/ Npp I01804040331/default.pdf
}

2000; Floresco et al, 2001; Cano-Cebrián et al, 2003). It is not clear how glutamatergic subicular terminals in NAc interact with dopaminergic terminals from ventral tegmental area (VTA) to regulate both the NAc DA levels and the locomotor output. Two hypotheses have been proposed to explain the increase in NAc DA extracellular levels. The first involves glutamatergic projections from the $\mathrm{VH}$ to the medial shell of the NAc and suggests that the glutamate released in NAc from these direct projections induces impulse-independent dopamine release by acting directly at dopaminergic terminals. This hypothesis is sustained by anatomical studies supporting the presence of presynaptic regulation by L-glutamate (L-Glu) on DA terminals in the NAc (Totterdell and Smith, 1989; Sesack and Pickel, 1990), and also by several reports showing that intra-NAc infusion of glutamate receptor antagonists prior to $\mathrm{VH}$ stimulation blocks both the motor activation and the increase in DA levels (Blaha et al, 1997; Taepavarapruk et al, 2000; CanoCebrián et al, 2003). The second hypothesis assumes that synaptic input to the VTA constitutes a critical link in the 
circuitry by which the VH modulates NAc DA levels. Thus, Legault et al (2000) showed that intra-VTA infusions of either tetrodotoxin or the glutamate receptor antagonist kynurenic acid were able to block the increase in NAc DA levels evoked by chemical stimulation of the VH. Floresco et al (2001) also showed that the number of spontaneously active DA neurons in VTA increased in a dose-dependent way after NMDA stimulation of the vSub, which presumes that it may enhance mesoaccumbens DA efflux.

In any case, it seems clear that NAc DA mediates the increase in locomotor activity provoked by NMDA stimulation of VH. Several reports show that systemic administration of DA antagonists counteracts both the electrical and NMDA-induced motor activation. For instance, intraperitoneal injections of SCH 23390 (a D1/D5 receptor antagonist) attenuated (at a dose of $0.25 \mathrm{mg} / \mathrm{kg}$ ) or completely abolished $(1.0 \mathrm{mg} / \mathrm{kg})$ the effect of electrical stimulation of the ventral subiculum on locomotor activity, whereas intraperitoneal pretreatment with the D2 antagonist sulpiride (at doses of 2 and $10 \mathrm{mg} / \mathrm{kg}$ ) was unable to attenuate the locomotor activation (Taepavarapruk et al, 2000). In another similar study, increased locomotor activity evoked by chemical stimulation of the VH was also abolished by the systemic administration of either $\mathrm{SCH}$ 23390 or haloperidol (a mixed DA D2/D1 receptor antagonist) (Bardgett and Henry, 1999).These results can be explained, at least in part, by the effects of the DA antagonists on the NAc of treated animals, since intra-NAc infusions of these antagonists are also able to block the motor activation (Yang and Mogenson, 1987). However, one cannot discard the involvement of VH DA receptors in the control of the excitatory responses to electrical or chemical stimulation of the $\mathrm{VH}$.

Several anatomical studies have shown that the ventral subicullum of hippocampus receives direct projections from midbrain DA neurons (Verney et al, 1985; Baulac et al, 1986; Gasbarri et al, 1991, 1994a, b, 1996). It is important to point out that different reports have shown that the hippocampo-striatal projections could be controlled by these dopaminergic projections. Thus, Verney et al (1985) showed that dopaminergic axons from the VTA reach the ventral and caudal parts of the hippocampal formation, their main targets being the subiculum and the adjacent CA1 hippocampal field. Interestingly, these authors also showed that this dopaminergic terminal field matches the area projecting toward the NAc which, together with the dopaminergic projection from the VTA, is clearly involved in the regulation of the exploratory locomotion (Mogenson and Nielsen, 1984; Wu et al, 1993). Later, an autoradiographic study (Kohler et al, 1991) demonstrated the existence of both D1 and D2 subtypes of dopamine receptors in the hippocampal formation providing additional support to the hypothesis of dopaminergic modulation of the hippocampo-striatal projections. However, until recently, the effects of this modulation have not been found in vivo. A recently published study shows that DA neurotransmission in VH is clearly involved in controlling the locomotor responses to NMDA stimulation (GiménezLlort et al, 2002). Bilateral local VH infusion of either the dopamine D1/D5 receptor antagonist SCH 23390 or the dopamine D2 receptor antagonist raclopride significantly antagonized the motor activation induced by NMDA, $\mathrm{SCH}$
23390 was found to be more potent than raclopride. These results strongly support the involvement of DA hippocampal systems in the control of the responses to NMDA stimulation and suggest that the VH DA receptors may also modulate the basal and the NMDA-stimulated NAc DA levels.

The present experiments were designed to explore in depth the capacity of $\mathrm{VH}$ DA receptors to modulate the neurochemical and behavioral responses evoked by $\mathrm{VH}$ administration of NMDA. We employed dual-probe microdialysis with concurrent measurement of the locomotor activity in rats in order to characterize: (i) the neurochemical consequences of blocking VH D1 or D2 receptors on NAc DA levels both in basal conditions and after NMDA stimulation of $\mathrm{VH}$; (ii) the capacity of the VH DA receptors to modulate the NMDA-induced locomotor activation.

\section{MATERIALS AND METHODS}

\section{Animals}

Male albino Wistar rats (340-360 g at the time of surgery) were used for the experiments. Prior to any treatment, the animals were kept for at least 1 week in our vivarium to adapt to the new conditions. The rats were housed, in groups of $4-6$, in plastic cages $\left(27 \times 50 \times 14 \mathrm{~cm}^{3}\right)$ with controlled humidity and temperature $\left(22^{\circ} \mathrm{C}\right)$ and a $12 / 12 \mathrm{~h}$ light/dark cycle (on 0800, off 2000) with free access to food and water. After the habituation period and before surgery, animals were handled daily for 1 week and placed in the open-field apparatus located in the experimental room for $1 \mathrm{~h}$ each day. All procedures were conducted in strict adherence to the EEC Council Directive 86/609 and Spanish laws (RD 223/1988) and policies on animal protection. Experiments were approved by the Animal Care Committee of the Faculty of Pharmacy of the University of Valencia.

\section{Drugs and Chemicals}

NMDA was purchased from Sigma Chemical Co (Madrid, Spain). The drug was freshly dissolved in artificial cerebrospinal fluid (aCSF) prior to use.

SCH 23390 and raclopride were also obtained from Sigma. A measure of $10 \mathrm{mM}$ stock solutions was prepared by dissolving the compound in the proper volume of $\mathrm{H}_{2} \mathrm{O}$. These solutions were then kept frozen as aliquots at $-40^{\circ} \mathrm{C}$ until use. Drugs were diluted from frozen aliquots with aCSF immediately before use. Drug solutions were properly protected from light exposure.

All other reagents were of the highest grade commercially available.

\section{Surgery}

Rats were anesthetized intraperitoneally with $400 \mathrm{mg} / \mathrm{kg}$ of chloral hydrate and placed in a stereotaxic apparatus. An incision $(8-10 \mathrm{~mm})$ was made in the skin over the skull and the wound margin was infiltrated with lidocaine (10\%). Four holes were drilled: two were used for the skull screws and the rest for the guide cannulae. Each animal was implanted unilaterally with two 20 gauge guide cannulae: one cannula was aimed at the NAc and the other at the VH. 
Coordinates relative to bregma and skull surface (Paxinos and Watson, 1986) were as follows: A/P: $+2.0 \mathrm{~mm}$; L: $+1.4 \mathrm{~mm}$; D/V: $-8.3 \mathrm{~mm}$ for the NAc cannula and A/P: $-6.0, \mathrm{~L}:-5.0, \mathrm{~V}:-8.5 \mathrm{~mm}$ for the $\mathrm{VH}$ cannula. Cannula assemblies were secured in place with dental cement. Two vertical concentric-type microdialysis probes with $2 \mathrm{~mm}$ of active membrane (Hospal AN69; molecular cutoff $60000 \mathrm{Da}$; Bologne, Italy) were constructed so that a length of dialysis membrane extended $4 \mathrm{~mm}$ (NAc) or $5 \mathrm{~mm}$ (VH) beyond the tip of the guide cannula. Microdialysis probes were inserted into the brain and fixed in place with dental cement. Following surgery, rats were housed in individual transparent plastic cages $\left(27 \times 27 \times 14 \mathrm{~cm}^{3}\right)$ in which they had free access to food and water. These cages were located side by side in order to prevent the influence of chronic stress on performance due to isolation.

\section{Microdialysis Procedure}

Microdialysis and behavioral experiments were carried out $48 \mathrm{~h}$ after the implantation of the probes. Five experimental groups were established ( $n=4$ /group). Experiments were made in the motor activity apparatus (see below) in order to simultaneously register the locomotor activity and the DA contents in dialysate samples from NAc. The probes were perfused with a solution of aCSF comprised $0.1 \mathrm{mM}$ aqueous phosphate buffer containing $147 \mathrm{mM} \mathrm{NaCl}$, $3.0 \mathrm{mM} \mathrm{KCl}, 1.3 \mathrm{mM} \mathrm{CaCl}$ and $1.0 \mathrm{mM} \mathrm{MgCl}_{2}(\mathrm{pH}=7.4)$ at a flow rate of $3.5 \mu \mathrm{l} / \mathrm{min}$. Fractions of dialysate were immediately analyzed for DA contents every $20 \mathrm{~min}$ by HPLC. Experimental treatments were initiated after a baseline had been established that was defined as, at least, three consecutive samples with less than $10 \%$ variations in DA content.

All drugs used in the experiments were dissolved in the aCSF fluid and infused via retrograde dialysis through the probe implanted in the VH. Pharmacological treatments involved the local application of $50 \mathrm{mM}$ NMDA for $10 \mathrm{~min}$ in the absence or presence of the dopamine D1/5 receptor antagonist SCH $23390(100$ and $250 \mu \mathrm{M})$ or the D2 receptor antagonist raclopride $(100$ and $250 \mu \mathrm{M})$. Either SCH 23390 or raclopride was infused through the dialysis probes before, during and after infusions of NMDA into the $\mathrm{VH}$. Specifically, the $\mathrm{VH}$ infusions of the DA receptor antagonists were initiated $30 \mathrm{~min}$ before the start of the NMDA infusion and lasted for an additional $20 \mathrm{~min}$ period after the end of the NMDA application. NMDA administrations were always initiated $100 \mathrm{~min}$ after the start of the experiment. The length of drug infusions is shown as a horizontal bar in the figures. Simultaneous to drug applications into the $\mathrm{VH}, \mathrm{NAc}$ dialysate samples were collected during dialysis of aCSF into the NAc.

Additionally, five control groups ( $n=4$ /group) were established. In the first control group, aCSF was perfused through the probe implanted in the $\mathrm{VH}$ throughout the experiment. In the other four control groups, SCH 23390 $(100$ or $250 \mu \mathrm{M})$ or raclopride $(100$ or $250 \mu \mathrm{M})$, respectively, were perfused through the probe implanted in $\mathrm{VH}$, following the same protocol used in the experimental groups. In all the control groups aCSF was simultaneously perfused in the NAc and dialysate samples were analyzed for their DA content.

Drug delivery and sample collection time were corrected for the lag time resulting from the dead volume of the inlet and outlet tubes used to connect the rat both to the syringe pump and the fraction collector, respectively.

\section{Analytical Procedure}

DA content in the samples was measured using an HPLC system with electrochemical detection. A Waters 515 series pump was used in conjunction with an electrochemical detector (Mod. Intro, Antec, Leyden, The Netherlands). The applied potential was $+0.7 \mathrm{~V}$ ( $v s \mathrm{Ag} / \mathrm{AgCl})$. Dialysates were manually injected onto a $5 \mu \mathrm{m}$ RP-18 column (LiCrhoCART 125-4, Merck, Darmstadt, Germany) via a Rheodyne valve fitted with a $50 \mu \mathrm{l}$ sample loop. The mobile phase consisted of a sodium acetate/acetic acid buffer $(0.1 \mathrm{M}, \mathrm{pH}=4.2)$ containing $60 \mathrm{mg} / \mathrm{l}$ of 1 -octanesulfonic acid, $100 \mathrm{mg} / \mathrm{l}$ of EDTA and $7.5 \mathrm{ml} / \mathrm{l}$ of methanol. Mobile phase was pumped through the column at a flow rate of $0.4 \mathrm{ml} / \mathrm{min}$. Chromatograms were integrated and compared with standards run separately on each experimental day, using an LCI-100 integrator (Perkin-Elmer, Norwalk, CT, USA). The detection limit was defined by a signal-to-noise ratio of $2: 1$ and it was approximately $4 \mathrm{fmol} / \mathrm{sample}$.

\section{Behavioral Testing and Motor Activity Apparatus}

For the experiments, rats were taken from the colony room and brought to the experimental room $10 \mathrm{~min}$ prior to each session. At that moment, the microdialysis probes were connected to the infusion pump and the fraction collector and continuously perfused at a flow rate of $3.5 \mu \mathrm{l} / \mathrm{min}$. After this initial period, experiments started, according to the protocol described in the microdialysis procedure section (see above). The behavioral apparatus consisted of a square wood arena $(60 \mathrm{~cm}$ long $\times 30 \mathrm{~cm}$ wide $\times 30 \mathrm{~cm}$ high) placed in a sound attenuated chamber. All experiments were recorded through a computerized video tracking system (SMART; Spontaneous Motor Activity Recording \& Tracking, Letica SA, Barcelona, Spain). Locomotor activity, measured as total distance travelled (cm) over 20 min periods, was automatically registered. The mean value of the distance travelled by rats in the three 20 min periods prior to experimental treatments was considered as the baseline. All values were expressed as a percent of the baseline that was defined as $100 \%$. The experimental room was illuminated with soft white light. The source of the light was indirect and regulated by a restate that was fixed in a position to provide the room with a low illumination.

\section{Histology}

Microdialysis probe placements were histologically examined on completing the experiments. Rats were anesthetized with chloral hydrate and the brain was fixed with $4 \%$ p-formaldehyde in $0.1 \mathrm{M}$ phosphate buffer, $\mathrm{pH} 7.4$, via transcardiac perfusion. Brains were carefully removed from the skull and postfixed overnight in $4 \%$ formaldehyde in phosphate buffer, $\mathrm{pH} 7.4$, at $4^{\circ} \mathrm{C}$. The brains were then 

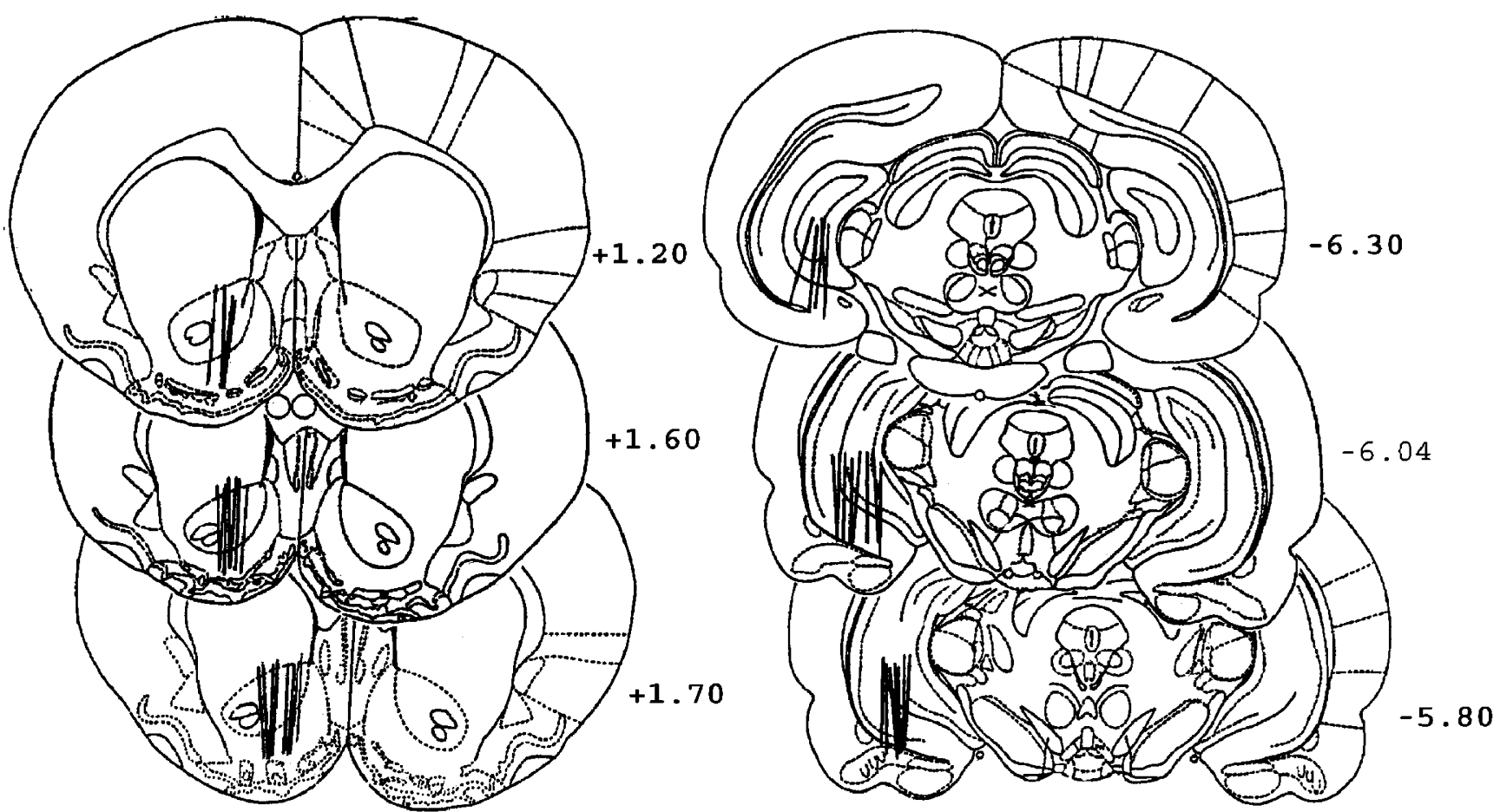

Figure I Representation of the locations of dialysis membranes in the present study. Plates are taken from Paxinos and Watson (1986) and the numbers beside each plate correspond to millimetres from bregma. In some cases, one plotted line corresponds to more than one dialysis membrane.

immersed in buffered $30 \%$ sucrose at $4^{\circ} \mathrm{C}$ until they sank, and $40 \mu \mathrm{m}$ thick coronal sections were obtained using a freezing microtome. All rats used in the study were confirmed to have the dialysis probes located in NAc and in the VH. The locations of microdialysis membranes are shown in Figure 1 .

\section{Data Analysis}

Neurochemical and behavioral data are expressed as a percentage of the baseline that was defined as $100 \%$. Treatment effects between groups were determined using two-way repeated-measures ANOVA with time as a repeated measure. After confirmation of significant main effects or interactions in the overall ANOVAs, data were further analyzed by simple effects ANOVA followed by Dunnet's multiple comparison test. The level of significance was set at $P<0.05$.

\section{RESULTS}

\section{Basal Values of Locomotor Activity and NAc DA Levels}

The average basal values of locomotor activity for the different experimental and control groups did not differ significantly. The average value, expressed as the total distance travelled by the rat in $20 \mathrm{~min}$, was $1030 \pm 47 \mathrm{~cm}$.

Similarly, the average basal values of DA in dialysates of the NAc for the different experimental and control groups (Table 1) were not statistically different. The average basal value was $1.91 \pm 0.48 \mathrm{fmol} / \mathrm{min}$.
Table I Average Basal Levels of DA in Nucleus Accumbens (mean \pm s.d.) for the Different Control and Experimental Groups

\begin{tabular}{lc} 
Groups & DA basal levels (fmol/min) \\
\hline aCSF & $1.85 \pm 0.56$ \\
Raclopride $100 \mu \mathrm{M}$ & $2.08 \pm 0.41$ \\
Raclopride $250 \mu \mathrm{M}$ & $1.82 \pm 0.52$ \\
$\mathrm{SCH} 23390100 \mu \mathrm{M}$ & $2.10 \pm 0.3 \mathrm{I}$ \\
$\mathrm{SCH} 23390250 \mu \mathrm{M}$ & $1.55 \pm 0.34$ \\
$\mathrm{NMDA}$ & $1.81 \pm 0.59$ \\
$\mathrm{NMDA}+$ Raclopride $100 \mu \mathrm{M}$ & $2.04 \pm 0.31$ \\
$\mathrm{NMDA}+$ Raclopride $250 \mu \mathrm{M}$ & $1.83 \pm 0.64$ \\
$\mathrm{NMDA}+\mathrm{SCH} 23390100 \mu \mathrm{M}$ & $1.97 \pm 0.54$ \\
$\mathrm{NMDA}+\mathrm{SCH} 23390250 \mu \mathrm{M}$ & $2.09 \pm 0.70$
\end{tabular}

Effects of Local Infusion SCH 23390 or Raclopride on Locomotor Activity and Extracellular NAc DA Levels

Neither $100 \mu \mathrm{M}$ (data not shown) nor $250 \mu \mathrm{M}$ SCH 23390 induced any significant change in locomotor activity $\left(\mathrm{F}_{(2,9)}=1.28\right.$; NS; Figure 2a). Similarly, the extracellular levels of DA in the ipsilateral NAc were not significantly modified after any treatment $\left(\mathrm{F}_{(2,9)}=1.26\right.$; NS; Figure $\left.2 \mathrm{~b}\right)$.

Similar results were obtained with raclopride. Retrodialysis application of $100 \mu \mathrm{M}$ (data not shown) or $250 \mu \mathrm{M}$ raclopride into $\mathrm{VH}$ did not produce any significant change in the locomotor activity of the tested animals $\left(\mathrm{F}_{(2,9)}=0.32\right.$; NS; Figure 2a) or in NAc DA levels $\left(\mathrm{F}_{(2,9)}=1.85\right.$; NS; Figure $2 b)$. 

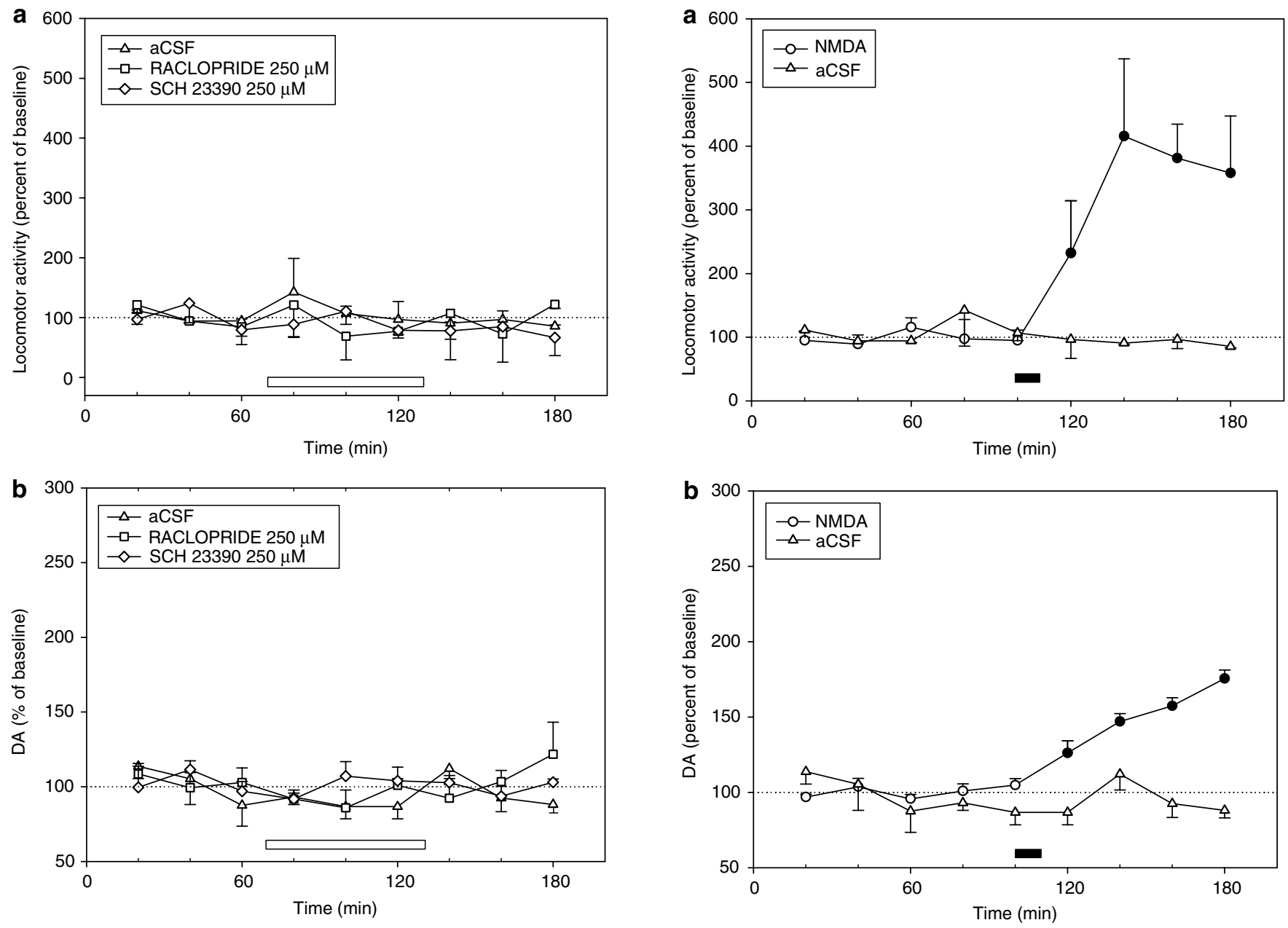

Figure 2 Effect of retrodialysis application of aCSF (triangle), $250 \mu \mathrm{M}$ $\mathrm{SCH} 23390$ (diamond), or $250 \mu \mathrm{M}$ raclopride (square) into the $\mathrm{VH}$ on (a) locomotor activity and (b) nucleus accumbens dopamine (NAc DA) ( $n=4 /$ group). For statistical purposes, the three baseline points were described as one. Data are expressed as mean percentage of baseline \pm s.e.m. The white bar indicates the length of perfusion. There was no difference in locomotor activity or NAc DA levels between animals administered with aCSF or DA receptor antagonists (two-way repeated measures across time ANOVA; see Results section). Similar results were obtained after the administration of $100 \mu \mathrm{M} \mathrm{SCH} 23390$ or $100 \mu \mathrm{M}$ raclopride (data not shown).

\section{Effects of NMDA Stimulation of the VH on Locomotor Activity and Extracellular DA Levels in the NAc}

Reverse dialysis of NMDA (50 mM, $10 \mathrm{~min}$ ) into the $\mathrm{VH}$ produced a robust and significant increase in motor activity (from 250 to $420 \%$ ) that remained high for, at least, $70 \mathrm{~min}$ following the NMDA stimulation. Two-way repeated measures ANOVA detected a significant drug treatment effect $\left(\mathrm{F}_{(1,6)}=15.08 ; \quad P=0.008\right)$ and drug treatment $\times$ sampling time interaction $\left(\mathrm{F}_{(6,36)}=7.58 ; P<0.0001\right)$. Simple main effect of sampling time for animals treated with NMDA was also statistically significant $\left(\mathrm{F}_{(6,18)}=6.65\right.$; $P<0.001$; Figure 3a).

NMDA application also produced a significant increase in DA levels in NAc (two-way ANOVA for drug treatment effect, $\mathrm{F}_{(1,6)}=400.9 ; P<0.0001$; dug treatment $\times$ sampling
Figure 3 Effect of retrodialysis application of $50 \mathrm{mMNMDA}$ into the $\mathrm{VH}$ (circle) on (a) locomotor activity and (b) nucleus accumbens dopamine (NAc DA) ( $n=4 /$ group). Data are expressed as mean percentage of baseline \pm s.e.m. The black bar indicates the length of NMDA perfusion. For statistical purposes the three baseline points were described as one. Twoway repeated measures across time ANOVA detected significant drug treatment effects both in locomotor activity and NAc DA levels (see text for significance data). Filled symbols indicate significant differences from baseline (simple main effects ANOVA with repeated measures across time followed by Dunnet's test, $P<0.05)$. Data from aCSF application into the $\mathrm{VH}$ (triangle; see Figure 2) are included for comparison.

time interaction, $\left.\mathrm{F}_{(6,36)}=18.46 ; P<0.0001\right)$; simple main effect for sampling time, $\mathrm{F}_{(6,18)}=31.46 ; \quad P<0.0001$; Figure 3b). DA levels significantly increased up to approximately $127 \%$ of the baseline $10 \mathrm{~min}$ after NMDA stimulation (Dunnet's test, $P<0.05$ ). The increase reached $178 \%$ of the baseline at the end of the experiment $(180 \mathrm{~min})$ (Dunnet's test, $P<0.05$; Figure $3 \mathrm{~b}$ ).

\section{Effects of SCH 23390 on the NMDA-Evoked Increase in Locomotor Activity and NAc DA Levels}

According to Figure 4a, hippocampal application by reverse dialysis of the dopamine D1 receptor antagonist SCH 23390 attenuated the increase in locomotor activity evoked by NMDA stimulation of the VH. Two-way repeated measures ANOVA with time as a repeated measure revealed a 
significant drug treatment effect $\left(\mathrm{F}_{(2,9)}=7.93, P=0.01\right)$ and drug treatment $\times$ time interaction $\left(\mathrm{F}_{(12,54)}=2.74\right.$, $P=0.006)$. Subsequent analysis of simple main effects (sampling time) confirmed that the lowest concentration tested $(100 \mu \mathrm{M})$ completely blocked the increase in the total distance travelled by the rats in such a way that the values obtained after stimulation did not significantly differ from their basal values $\left(\mathrm{F}_{(6,18)}=2.40\right.$; NS; Figure $\left.4 \mathrm{a}\right)$.

Surprisingly, $250 \mu \mathrm{M}$ SCH 23390 was not able to completely suppress the increase in locomotor activity evoked by NMDA application. The locomotor activity registered 10 and $30 \mathrm{~min}$ (120 and $140 \mathrm{~min}$ in Figure 4a) after VH stimulation was significantly higher than the basal activity in this experimental group $\left(\mathrm{F}_{(6,18)}=4.24 ; P=0.008\right.$; Dunnet's test, $P<0.05$; Figure 4a). Nevertheless, Dunnet's test revealed that the locomotor activity registered during the last $40 \mathrm{~min}$ (corresponding to 160 and $180 \mathrm{~min}$ in Figure 4a) did not differ from the basal values.
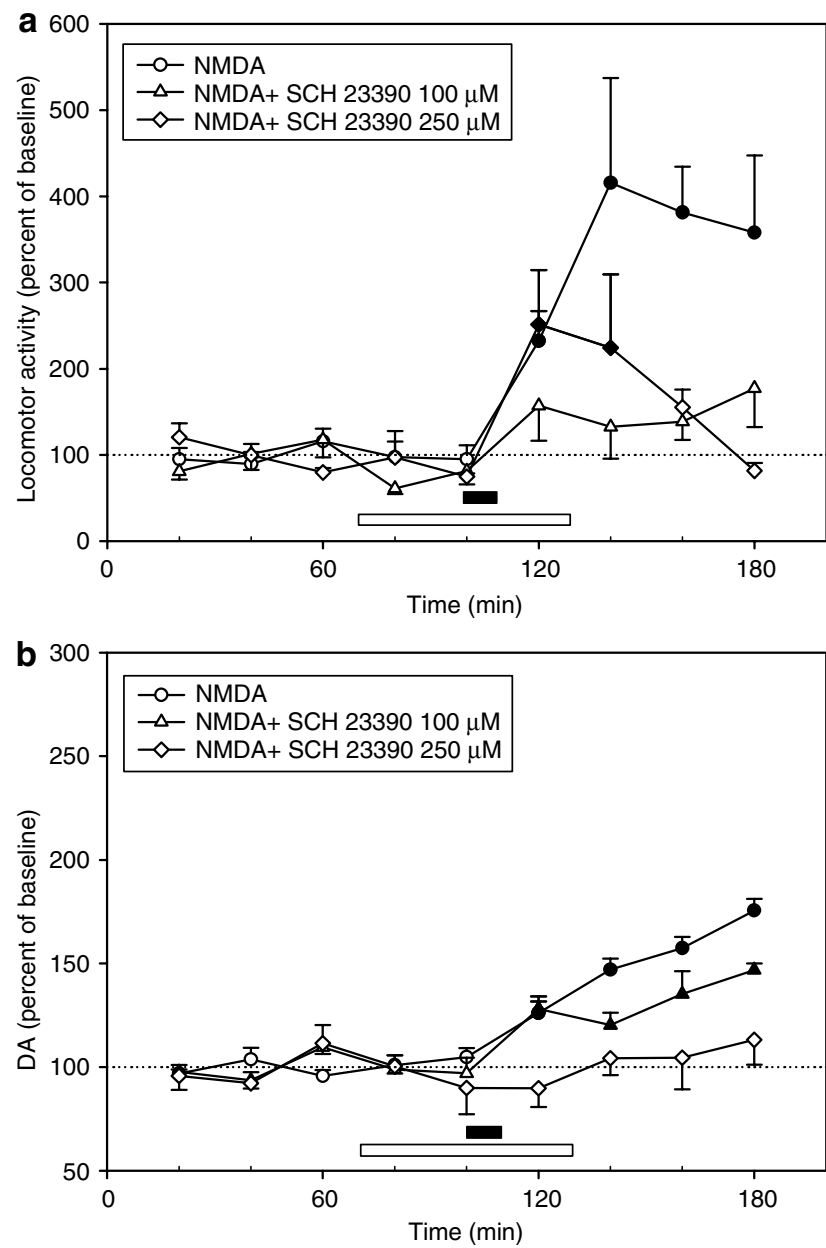

Figure 4 Effect of retrodialysis application of SCH 23390 at $100 \mu \mathrm{M}$ (triangle) and $250 \mu \mathrm{M}$ (diamond) in combination with $50 \mathrm{mM}$ NMDA into the $\mathrm{VH}$ on (a) locomotor activity and (b) nucleus accumbens dopamine (NAc DA) levels ( $n=4 /$ group). Data are expressed as mean percentage of baseline \pm s.e.m. The white and black bars indicate the length of $\mathrm{SCH}$ 23390 and NMDA perfusions, respectively. For statistical purposes, the three baseline points were described as one. Data from $50 \mathrm{mM}$ NMDAtreated animals (circle; see Figure 3) are included for comparison. Filled symbols indicate significant differences (simple main effects ANOVA with repeated measures across time followed by Dunnet's test, $P<0.05)$ from the respective baseline (see text for significance data).
On the other hand, local application of SCH 23390 was also able to block the increase in DA levels induced by NMDA stimulation of the VH (Figure 4b). Two-way repeated measures ANOVA showed a significant drug treatment effect $\left(\mathrm{F}_{(2,9)}=10.61 ; P=0.004\right)$ and a significant interaction between drug treatment groups and sampling time $\left(\mathrm{F}_{(12,54)}=4.90 ; P<0.0001\right)$. Subsequent analysis of the sampling time effect corroborated that $100 \mu \mathrm{M}$ SCH 23390 did not suppress the increase in NAc DA levels over time $\left(\mathrm{F}_{(6,18)}=16.42 ; \quad P<0.0001\right)$. However, the retrodialysis application of $250 \mu \mathrm{M}$ SCH 23390 completely blocked the increase in NAc DA levels after the stimulation $\left(\mathrm{F}_{(6,18)}=1.23\right.$; NS; Figure $\left.4 \mathrm{~b}\right)$.

\section{Effects of Raclopride on Locomotor Activity and NAc DA Levels Evoked by NMDA Stimulation of the VH}

Raclopride perfusion during $60 \mathrm{~min}$ into the $\mathrm{VH}$ was able to reduce the increase in locomotor activity evoked by NMDA stimulation of this brain area. Two-way repeated measures ANOVA with time as a repeated measure revealed a significant drug treatment effect $\left(\mathrm{F}_{(2,9)}=5.64, P=0.026\right)$ and drug treatment $\times$ time interaction $\left(\mathrm{F}_{(12,54)}=2.69\right.$, $P=0.007)$. Subsequent analysis of simple main effects (sampling time) confirmed that the lowest concentration tested $(100 \mu \mathrm{M})$ completely blocked the increase in the total distance travelled by the rats $\left(\mathrm{F}_{(6,18)}=2.15\right.$; NS; Figure $\left.5 \mathrm{a}\right)$. On the other hand, the statistical analysis revealed differences with respect to the basal values $\left(\mathrm{F}_{(6,18)}=3.10\right.$; $P=0.029)$ in the $250 \mu \mathrm{M}$ raclopride-treated animals, though Dunnet's test showed that these differences only appeared at the end of the experiment (Figure 5a). It is worth highlighting that in both groups the decrease in the locomotor activation was accompanied by the appearance of clonic seizure activity in $75 \%$ of the raclopride-treated animals (12 of 16 rats) in the late phase of the experiment (from 140 to $180 \mathrm{~min}$ ).

Two-way repeated measures ANOVA did not detect drug treatment effects on NAc DA efflux evoked by NMDA application into $\mathrm{VH}$ in the raclopride-treated rats, although revealed a significant drug treatment $\times$ time interaction $\left(\mathrm{F}_{(12,54)}=6.96 ; P<0.0001\right.$; Figure $\left.5 \mathrm{~b}\right)$. As can be observed, DA levels showed a dramatic and significant increase compared to their basal values in the late phase of the experiments $\left(100 \mu \mathrm{M}: \mathrm{F}_{(6,18)}=33.06 ; P<0.0001 ; 250 \mu \mathrm{M}\right.$ : $\mathrm{F}_{(6,18)}=19.45 ; P<0.0001$; Figure $\left.5 \mathrm{~b}\right)$ coinciding with the appearance of signs of clonic seizure activity.

\section{DISCUSSION}

The present study provides new insights into the mechanisms involved in the locomotor activation and increase in NAc DA levels in response to VH chemical stimulation. Our data provide clear evidence of the modulatory role played by the ventral hippocampal D1 and D2 receptors in both locomotor activation and increasing NAc DA levels, in rats, after NMDA stimulation of the VH. In particular, blocking D1 receptors in $\mathrm{VH}$ by SCH 23390, within the range of concentrations tested, is able to attenuate or completely block both the NMDA-evoked increase in NAc DA levels and the locomotor activation. On the other hand, the D2 

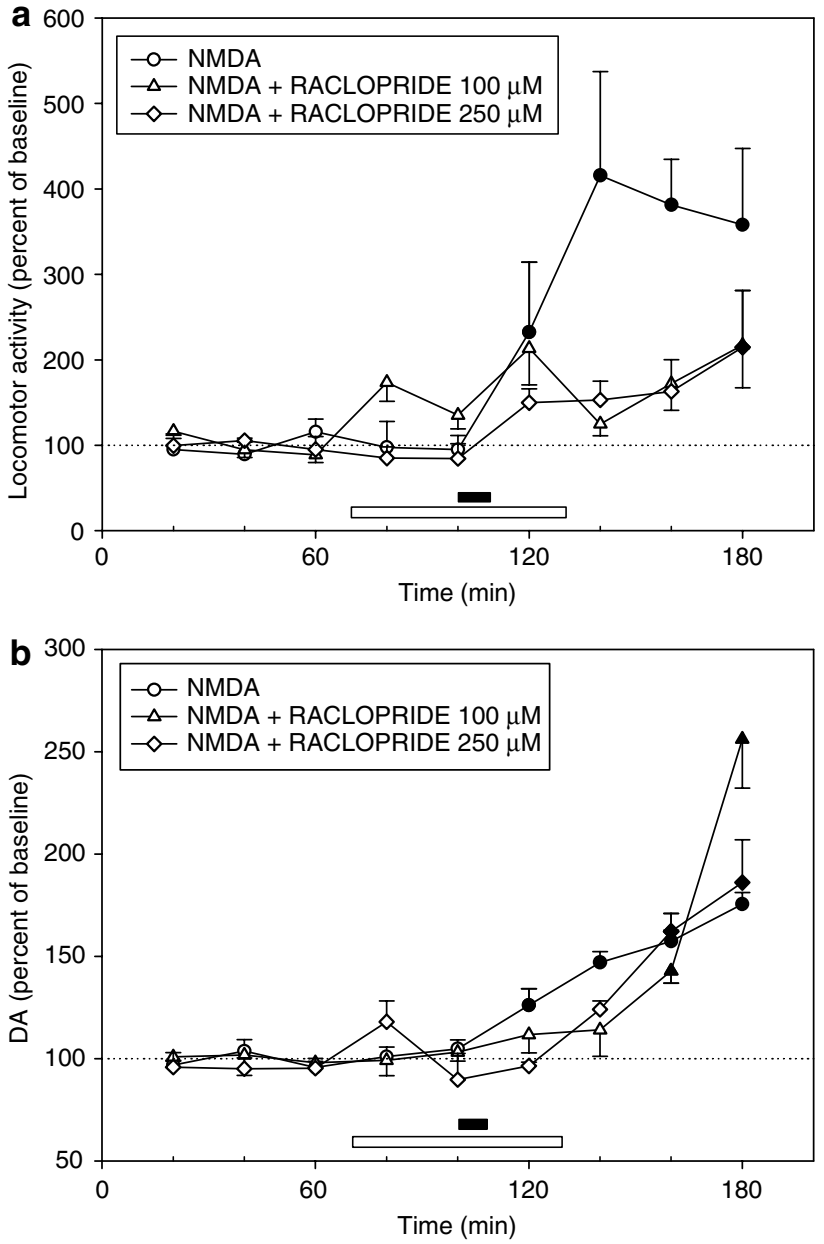

Figure 5 Effect of retrodialysis application of raclopride at $100 \mu \mathrm{M}$ (triangle) and $250 \mu \mathrm{M}$ (diamond) in combination with $50 \mathrm{mM}$ NMDA into the $\mathrm{VH}$ on (a) locomotor activity and (b) nucleus accumbens dopamine (NAc DA) levels ( $n=4 /$ group). Data are expressed as mean percentage of baseline \pm s.e.m. The white and black bars indicate the length of raclopride and NMDA perfusions, respectively. For statistical purposes the three baseline points were described as one. Data from $50 \mathrm{mM}$ NMDA-treated animals (circle; see Figure 3) are included for comparison. Filled symbols indicate significant differences (simple main effects ANOVA with repeated measures across time followed by Dunnett's test, $P<0.05)$ from the respective baseline (see text for significance data).

receptor blockade displays a complex effect: it initially attenuates the locomotor activation and the NAc DA level enhancement but later leads to the appearance of clonic seizure activity that coexists with a dramatic increase in NAc DA levels. Our results also show that the blockade of both D1 and D2 receptors does not modify basal locomotion or basal NAc DA levels.

\section{Methodological Considerations}

The majority of the studies dealing with the effects of VH chemical stimulation on NAc DA levels and/or locomotor activity have used unilateral or bilateral microinjections of NMDA in their experimental protocol. In contrast, we have selected the retrodialysis method to administer the drug. Although this methodology does not let us know the exact quantity of the drug to reach the tissue of interest, given several factors affecting recovery in vivo from a microdialysis probe, by contract retrodialysis offers a clear advantage compared to the microinjection technique in that it allows constant extracellular drug concentrations to be maintained in the application site through the experiment. This point can be of crucial importance when a sustained blockade of a receptor complex is part of the objective, as was the case in this study.

When retrodialysis is used to deliver the drug/s of interest, it is necessary to select the drug concentration properly in the perfusate as well as the infusion time. In the present study, the concentration and the time of NMDA infusion were selected on the basis of our previous experiments (Cano-Cebrián et al, 2003) in order to: (i) minimize the clonic seizure activity associated with high doses of NMDA (Bardgett and Henry, 1999), which could mask the NMDA-evoked increase in locomotion. By using the present administration protocol $(50 \mathrm{mM}$ NMDA, $10 \mathrm{~min}$, perfusion rate $3.5 \mu \mathrm{l} / \mathrm{min}$ ), the signs of clonic seizure activity (rearing, forelimb tremor, facial tics and falling over backwards) were not observed in the NMDA-treated group; (ii) ensure a rapid onset of the NMDA effects after drug application; in this respect, we adapted the NMDA infusion time used in our previous experiments from 40 to $10 \mathrm{~min}$ and the NMDA concentration in perfusate from 5 to $50 \mathrm{mM}$. Under these conditions, the increase in NAc DA levels was detected in the first sample $(10 \mathrm{~min})$ after switching the syringe from NMDA solution to aCSF, which contrasts clearly with the 40-60-min delay observed in our previous protocol (Cano-Cebrián et al, 2003) and (iii) shorten the duration of the experiment. Retrodialysis application of NMDA solutions with the present protocol led to a similar increase in NAc DA levels $(\approx 150 \%$ of baseline $)$ to that observed in our previous paper (Cano-Cebrián et al, 2003) and in other microinjection studies (Legault and Wise, 1999; Legault et al, 2000).

Similarly, concentrations of raclopride and SCH 23390 were derived from a previous in vivo microdialysis study (Santiago et al, 1993) and conveniently adapted to offset differences in microdialysis methodological factors such as perfusion flow rate and effective length of dialysis membrane. It should be remembered that in a retrodialysis experiment the perfusion flow rate and the length of the active portion of the dialysis membrane strongly affect the effective dose that leaves the dialysis probe and reaches the extracellular space of the brain tissue (Kehr, 1993; Stenken, 1999). In this sense, although the concentrations of the DA antagonists used in the present experiments are higher than those reported in the referenced study and in other studies, it must be taken into account that under our conditions the perfusion flow rate was $3.5 \mu \mathrm{l} / \mathrm{min}$, clearly higher than that used in the study above cited $(1.5 \mu \mathrm{l} / \mathrm{min})$. Moreover, the exposed length of the dialysis membrane was $2 \mathrm{~mm}$, instead of the $3 \mathrm{~mm}$ used in the reference study.

\section{Influence of Local D1 or D2 Receptor Antagonism on the Locomotor Activation Induced by NMDA Stimulation}

Blockade of D1 receptors in $\mathrm{VH}$ appears to exert a clear inhibitory effect on the NMDA-evoked locomotor activation. In our experiments, retrodialysis application of $\mathrm{SCH}$ 
23390 reduced or completely blocked the locomotor activation. This blockade persisted until the end of the experiment. As clonic seizure activity was not observed in the SCH 23390-NMDA-treated animals, the reduction in locomotor activity detected in these animals can be attributed to an inhibitory effect of SCH 23390 on the NMDA-induced activation. On the contrary, although raclopride was also capable of reducing the effects of NMDA on locomotor activity, its effects were not as persistent as those produced by SCH 23390. In fact, the locomotor activity increased to $210 \%$ of the baseline after removing the antagonist from the perfusion fluid, which was a statistically significant increase (Figures $4 a$ and $5 a$ ). Another important finding was the appearance of clonic seizure activity in the last phase of the raclopride experiments. In animals treated with raclopride, we observed mild symptoms of akinesia preceding the apparition of the clonic seizure activity. Importantly, the seizure activity, which was detected in $75 \%$ of the racloprideNMDA-treated animals, occurred simultaneously with the increase in DA levels (Figure 5b).

On the other hand, neither SCH 23390 nor raclopride altered the basal locomotor activity. This observation indicates that stimulation of $\mathrm{D} 1$ or $\mathrm{D} 2$ receptors in $\mathrm{VH}$ is not necessary for basal locomotor activity. Although it is clear that NMDA stimulation of $\mathrm{VH}$ increases locomotor activity, several authors have reported that ventral hippocampal activity is not required for basal locomotion. So, lidocaine infusions into the $\mathrm{VH}$ did not suppress ongoing locomotor activity (Bardgett and Henry, 1999). Hippocampus plays a central role in novelty detection and explicit memory and, both cognitive functions, involve locomotor adaptative responses. In the above studies, similarly to our study, basal locomotor activity was registered after a period of habituation to the open-field chamber. Under these conditions, one could expect that animals are not learning new spatial information, and consequently, the functional relevance of the $\mathrm{VH}$ should be reduced. Indeed, $\mathrm{Li}$ et al (2003) showed that brief exposure to a novel environment lowered the threshold for the induction of hippocampal neuroplasticity. This effect was lost in the animals exploring a familiar environment.

Several authors have previously studied the effects of systemically administered DA antagonist on the locomotor activation in rodents evoked by electrical or chemical stimulation of the VH. For instance, Taepavarapruk et al (2000) showed that intraperitoneal injections with SCH 23390 attenuated (at a dose of $0.25 \mathrm{mg} / \mathrm{kg}$ ) or completely abolished $(1.0 \mathrm{mg} / \mathrm{kg})$ the effect of electrical stimulation of the ventral subiculum on locomotor activity, whereas intraperitoneal pretreatment with the D2 antagonist sulpiride (at doses of 2 and $10 \mathrm{mg} / \mathrm{kg}$ ) was unable to attenuate the locomotor activation. Bardgett and Henry (1999) reported that the increase in locomotor activity evoked by chemical stimulation of the $\mathrm{VH}$ was abolished by the systemic administration of SCH $23390(0.1 \mathrm{mg} / \mathrm{kg}$ i.p.) or the mixed D2/D1 receptor antagonist haloperidol $(0.13 \mathrm{mg} / \mathrm{kg}$ i.p. $)$. In this last case, authors explained their results assuming a blockade of D1 and D2 receptors located in NAc. Our present results suggest that, at least, some of the abovementioned inhibitory effects of the systemically administered DA antagonists reported by Bardgett and Henry, could be due to the direct action of these drugs on the VH DA receptors.

Our behavioral findings are also in close agreement with recent studies on this subject. Giménez-Llort et al (2002) showed that SCH 23390 and raclopride microinjected locally into the $\mathrm{VH}$ significantly antagonized the motor activation evoked by simultaneous microinjections of NMDA; as occurred in our study, neither raclopride nor SCH 23390 induced any significant change in motor activity compared with the control group. Consistent with our data, these authors also reported that, apparently, in terms of attenuating NMDA-evoked activation SCH 23390 was more powerful than raclopride. This fact could be indicative, as Giménez-Llort et al pointed out, that dopamine receptors of the D1/5 subtype are particularly involved in controlling the NMDA receptor-mediated effects in the VH. However, other explanations are possible. For instance, differences in the clearance mechanisms involved in eliminating these drugs from the extracellular space and, therefore, a different persistence in the application site, could explain these results. Another valid explanation could be the above mentioned appearance of mild symptoms of akinesia preceding clonic seizure activity in the raclopride-NMDA treated animals, although the authors did not mention this. This is not the first time that phenomena like these have been reported in the bibliography dealing with the chemical stimulation of VH (Sacaan and Schoepp, 1992; Bardgett and Henry, 1999). In our experiments, the seizure activity was observed quite near the end of raclopride perfusion and, interestingly, it was concomitant with the dramatic increase in NAc DA levels detected in this experimental group (see below).

\section{Influence of Local D1 or D2 Receptor Antagonism on the NAc DA Levels Increase Induced by NMDA Stimulation}

The present study shows, for the first time, that both D1 and D2 receptors are able to modulate the NAc DA efflux evoked by NMDA stimulation of the VH. SCH 23390 attenuated the increase in NAc DA levels observed after ventral hippocampal NMDA application. The attenuating effect was persistent and lasted until the end of the experiment. Raclopride also showed an initial attenuating effect on the increase in the NAc DA levels. However, this initial attenuating phase was followed by an important increase in NAc DA levels after the end of the antagonist application. The enhancement reached almost $260 \%$ of baseline for $100 \mathrm{mM}$ and $190 \%$ for $250 \mathrm{mM}$ raclopride, and was accompanied at the behavioral level by clonic seizure activity in $75 \%$ of the treated animals. Supporting the relationship between NAc-DA and clonic seizures, Whittington et al (2002) observed and increase in NAc-DA during cocaine-induced seizures. In addition, they demonstrated that intra-accumbal administration of exogenous DA increased the susceptibility to cocaine-evoked seizures.

Another important observation was that neither $\mathrm{SCH}$ 23390 nor raclopride directly infused into the $\mathrm{VH}$ altered the basal DA levels in NAc. This fact was also in accordance with the lack of effect these drugs have on basal locomotor activity. As we describe above, Li et al (2003) showed that 
brief exposure to a novel environment, but not a familiar one, facilitated hippocampal neuroplasticity. Moreover, hippocampal neuroplasticity was dependent on activation of D1/D5 receptors when animals were exposed to novelty, because D1 antagonist SCH 23390 blocked LTP in the VH and D1 agonist SKF 38393 promoted the same effects as novelty on the hippocampal LTP. Thus, it seems that DA only modulates the excitability of hippocampal neurons if the neurons are active and processing some kind of environmental information.

There are few detailed studies about how DA affects synaptic transmission in the $\mathrm{VH}$. Our data suggest that DA receptors exert a modulatory effect on NMDA receptormediated responses in $\mathrm{VH}$. However, the exact nature of this modulation is not clear. So, according to our results, DA seems to potentiate the responses of the $\mathrm{VH}$ neurons to NMDA through D1 receptors. However, its effects through D2 receptors are not so evident. A considerable body of data shows that DA affects glutamate function, their effects differing according to several factors, among which, the DA receptor subtype, the brain area studied and the type of preparation (in vitro vs in vivo) are of great importance (for reviews, see, Nicola et al, 2000; West et al, 2003).

Studies in vivo have reported an excitatory effect of D1 receptors on NMDA activation in the prefrontal cortex and the striatum (Gonon, 1997; Wang and O'Donnell, 2001; West and Grace, 2002; Tseng and O'Donnell, 2004). Inversely, D2 receptor activation decreased the excitability of the prefrontal and striatal neurons (West and Grace, 2002). In our study, strong evidence is provided that locomotor activity and NAc-DA efflux, evoked by ventral hippocampal NMDA stimulation, require D1 receptor activation. Some recent data may enlighten the functional interpretation of the present results. As we comment above, Li et al (2003) demonstrated that in a novel environment the induction of activity-dependent, persistent increases in glutamatergic transmission in CA1 synapses was facilitated by $\mathrm{D} 1 / \mathrm{D} 5$ receptors. In such a situation, it is very probable that the hippocampus is being activated by multiple glutamatergic projections from the prefrontal cortex, the amygdala, and other sensory relays. The effects of exogenous infusion of NMDA into the $\mathrm{VH}$ resemble this natural neuronal activation and, consequently, should be modulated by D1/D5 receptors.

In conclusion, our data clearly indicate that D1 and D2 receptors are able to modulate NMDA responses in the $\mathrm{VH}$ and leave the possibility open that $\mathrm{D} 1$ and $\mathrm{D} 2$ receptors could modulate transmission in $\mathrm{VH}$ either directly or perhaps through complex processes. More exact studies using, for example, in vivo intracellular recordings combined with retrodialysis application of drugs, are necessary to throw light on the complex nature of the interactions described here.

\section{ACKNOWLEDGEMENTS}

This research was supported by a grant from the Plan Nacional Sobre Drogas (PNSD) of Ministerio de Interior of Spain. MJCC is a recipient of a Predoctoral Fellowship from the PNSD.

\section{REFERENCES}

Bardgett ME, Henry JD (1999). Locomotor activity and accumbens Fos expression driven by ventral hippocampal stimulation require D1 and D2 receptors. Neuroscience 94: 59-70.

Baulac M, Verney C, Berger B (1986). Dopaminergic innervation of the parahippocampal and hippocampal regions in the rat. Rev Neurol (Paris) 142: 895-905.

Blaha CD, Yang CR, Floresco SB, Barr AM, Phillips AG (1997). Stimulation of the ventral subiculum of the hippocampus evokes glutamate receptor-mediated changes in dopamine efflux in the rat nucleus accumbens. Eur J Neurosci 9: 902-911.

Brudzynski SM, Gibson CJ (1997). Release of dopamine in the nucleus accumbens caused by stimulation of the subiculum in freely moving rats. Brain Res Bull 42: 303-308.

Cano-Cebrián MJ, Zornoza-Sabina T, Guerri C, Polache A, Granero $\mathrm{L}$ (2003). Acamprosate blocks the increase in dopamine extracellular levels in nucleus accumbens evoked by chemical stimulation of the ventral hippocampus. Naunyn Schmiedebergs Arch Pharmacol 368: 324-327.

Floresco SB, Todd CL, Grace AA (2001). Glutamatergic afferents from the hippocampus to the nucleus accumbens regulate activity of ventral tegmental area dopamine neurons. J Neurosci 21: 4915-4922.

Gasbarri A, Campana E, Pacitti C, Hajdu F, Tombol T (1991). Organization of the projections from the ventral tegmental area of Tsai to the hippocampal formation in the rat. J Hirnforsch 32: 429-437.

Gasbarri A, Packard MG, Campana E, Pacitti C (1994a). Anterograde and retrograde tracing of projections from the ventral tegmental area to the hippocampal formation in the rat. Brain Res Bull 33: 445-452.

Gasbarri A, Packard MG, Sulli A, Pacitti C, Innocenzi R, Perciavalle $\mathrm{V}$ (1996). The projections of the retrorubral field A8 to the hippocampal formation in the rat. Exp Brain Res 112: 244-252.

Gasbarri A, Verney C, Innocenzi R, Campana E, Pacitti C (1994b). Mesolimbic dopaminergic neurons innervating the hippocampal formation in the rat: a combined retrograde tracing and immunohistochemical study. Brain Res 668: 71-79.

Giménez-Llort L, Wang FH, Ogren SO, Ferre S (2002). Local dopaminergic modulation of the motor activity induced by $\mathrm{N}$ methyl-D-aspartate receptor stimulation in the ventral hippocampus. Neuropshychopharmacology 26: 737-743.

Gonon F (1997). Prolonged and extrasynaptic excitatory action of dopamine mediated by $\mathrm{D} 1$ receptors in the rat striatum in vivo. J Neurosci 17: 5972-5978.

Kehr J (1993). A survey on quantitative microdialysis: theoretical models and practical implications. J Neurosci Methods 48: 251-261.

Kohler C, Ericson H, Radesater AC (1991). Different laminar distributions of dopamine D1 and D2 receptors in the rat hippocampal region. Neurosci Lett 126: 107-109.

Legault M, Rompre PP, Wise RA (2000). Chemical stimulation of the ventral hippocampus elevates nucleus accumbens dopamine by activating dopaminergic neurons of the ventral tegmental area. J Neurosci 20: 1635-1642.

Legault M, Wise RA (1999). Injections of $N$-methyl-D-aspartate into the ventral hippocampus increase extracellular dopamine in the ventral tegmental area and nucleus accumbens. Synapse 31: 241-249.

Li S, Cullen WK, Anwyl R, Rowan MJ (2003). Dopamine-dependent facilitation of LTP induction in hippocampal CA1 by exposure to spatial novelty. Nat Neurosci 6: 526-531.

Mogenson GJ, Nielsen M (1984). Neuropharmacological evidence to suggest that the nucleus accumbens and subpallidal region contribute to exploratory locomotion. Behav Neural Biol 42: $52-60$. 
Nicola SM, Surmeier J, Malenka RC (2000). Dopaminergic modulation of neuronal excitability in the striatum and nucleus accumbens. Annu Rev Neurosci 23: 185-215.

Paxinos G, Watson C (1986). The Rat Brain in Stereotaxic Coordinates. Academic Press: New York.

Sacaan AI, Schoepp DD (1992). Activation of hippocampal metabotropic excitatory amino acid receptors leads to seizures and neuronal damage. Neurosci Lett 139: 77-82.

Santiago M, Machado A, Cano J (1993). Regulation of prefrontal cortical dopamine release by dopamine receptor agonists and antagonists. Eur J Pharmacol 239: 83-91.

Sesack SR, Pickel VM (1990). In the rat medial nucleus accumbens, hippocampal and catecholaminergic terminals converge on spiny neurons and are in apposition to each other. Brain Res 527: 266-279.

Stenken JA (1999). Methods and issues in microdialysis calibration. Anal Chim Acta 379: 337-358.

Taepavarapruk P, Floresco SB, Phillips AG (2000). Hyperlocomotion and increased dopamine efflux in the rat nucleus accumbens evoked by electrical stimulation of the ventral subiculum: role of ionotropic glutamate and dopamine D1 receptors. Psychopharmacology 151: 242-251.

Totterdell S, Smith AD (1989). Convergence of hippocampal and dopaminergic input onto identified neurons in the nucleus accumbens of the rat. J Chem Neuroanat 2: 285-298.

Tseng KY, O'Donnell P (2004). Dopamine-glutamate interactions controlling prefrontal cortical pyramidal cell excitability involve multiple signaling mechanisms. J Neurosci 24: 5131-5139.
Verney C, Baulac M, Berger B, Alvarez C, Vigny A, Helle KB (1985). Morphological evidence for a dopaminergic terminal field in the hippocampal formation of young and adult rat. Neuroscience 14: 1039-1052.

Wang J, O'Donnell P (2001). D(1) dopamine receptors potentiate NMDA-mediated excitability increase in layer $\mathrm{V}$ prefrontal cortical pyramidal neurons. Cerebr Cortex 11: 452-462.

West AR, Floresco SB, Charara A, Rosenkranz JA, Grace AA (2003). Electrophysiological interactions between striatal glutamatergic and dopaminergic systems. Ann NY Acad Sci 1003: 53-74.

West AR, Grace AA (2002). Opposite influences of endogenous dopamine D1 and D2 receptor activation on activity states and electrophysiological properties of striatal neurons: studies combining in vivo intracellular recordings and reverse microdialysis. J Neurosci 22: 294-304.

Whittington RA, Virag L, Vulliemoz Y, Cooper TB, Morishima HO (2002). Dexmedetomidine increases the cocaine seizure threshold in rats. Anesthesiology 97: 693-700.

Wu M, Brudzynski SM, Mogenson GJ (1993). Functional interaction of dopamine and glutamate in the nucleus accumbens in the regulation of locomotion. Can J Physiol Pharmacol 71: 407-413.

Wu M, Brudzynski SM (1995). Mesolimbic dopamine terminals and locomotor activity induced from the subiculum. Neuroreport 6: 1601-1604.

Yang CR, Mogenson GJ (1987). Hippocampal signal transmission to the pedunculopontine nucleus and its regulation by dopamine D2 receptors in the nucleus accumbens: an electrophysiological and behavioural study. Neuroscience 23: 1041-1055. 